\title{
Periprostetik enfeksiyon riskini azaltma: ameliyathane ortamı ve ameliyat sırasında alınacak önlemler
}

\author{
Minimising the risk of periprosthetic infection: operative environment and \\ peri-operative measures
}

\author{
Ibrahim Azboy
}

Thomas Jefferson University, Rothman Institute, Philadelphia, USA

\begin{abstract}
Total eklem artroplastileri, giderek daha fazla sayıda uygulanan, başarılı ameliyatlardır. Periprostetik eklem enfeksiyonları, total eklem artroplastilerinin en yıkıcı komplikasyonları arasındadır. Bu komplikasyon, ortopedistler için ciddi bir sorun olarak durmaya devam etmektedir. Periprostetik eklem enfeksiyonlarının tedavisi zordur ve hastaya çoğu zaman birden fazla ameliyat gerekmektedir. Ayrıca, ülke ekonomisine ek yük getirmektedir. Ortopedik cerrahide enfeksiyonla mücadelenin en önemli tarafı, enfeksiyonu önlemektir.

Enfeksiyonu önlemek amacıyla birçok strateji geliştirilmiştir. Bu konuda çok sayıda çalışma yapılmaya devam etmektedir. Bu derlemede, periprostetik eklem enfeksiyonlarını önlemek için ameliyat öncesinde, sırasında ve sonrasında alınması gereken tedbirler sunulacaktır.
\end{abstract}

Anahtar sözcükler: total eklem artroplastisi; periprostetik eklem enfeksiyonu; ameliyathane ortamı; kanama
Total joint arthroplasties (TJA) are successful operations and nowadays the number of TJA has increased considerably. Prosthetic joint infection (PJI) is one of the most devastating complications in TJA. This complication continues to be a challenge to orthopaedic surgeons. The treatment of $\mathrm{PJI}$ is difficult and it generally requires more than a single operation. Moreover, PJI adds additional burden to the health care system of a country. One of the most important aspects of infection in orthopedic surgery is to prevent infection.

Numerous strategies have been developed for the prevention of infection. The literature on this subject is also enormous. The aim of this review is to present the measures for the prevention of $\mathrm{PJI}$ during pre-, intra-, and post-operative periods.

Key words: total joint arthroplasty; periprosthetic infection; operating room environment; bleeding
T otal eklem artroplastileri (TEA), ağrııı gideren ve fonksiyonları geri kazandıran başarılı ameliyatlardır. ${ }^{[1]} \mathrm{TEA}$, günümüzde giderek daha fazla sayıda uygulanmaktadır. Periprostetik eklem enfeksiyonu (PPE), eklem artroplastisi sonrası karşılaşılan nadir bir komplikasyondur. Ancak, tedavisi zordur ve hastaya çoğu zaman birden fazla ameliyat gerekmektedir. Ayrıca, yaşlı nüfusun, obezitenin ve eşlik eden hastalıkların artmasına paralel olarak, PPE'nin insidansında da artış görülmektedir. ${ }^{[2]}$ PPE, hastaların morbidite ve mortalitesini arttıran en yıkıcı komplikasyonlar arasındadır. ${ }^{[3]}$ PPE'nin tedavisi, hem hasta hem de hekim açısından oldukça zordur. Üstelik bu, ülke ekonomisine de ek yük getirmektedir. ${ }^{[4]}$ Ortopedik cerrahide enfeksiyonla mücadelenin en önemli tarafı enfeksiyonu önlemektir. ${ }^{[5]}$ Bu nedenle, PPE'nin önlenmesi için çaba gösterilmesi gerekmektedir. Bu amaçla; hastaya ait risk faktörlerini belirlenmesi, ameliyathane koşullarının en uygun hale getirilmesi, antibiyotik profilaksisi ve kanama kontrolü önem kazanmaktadır. Periprostetik enfeksiyonların gelişmesini önlemek için, cerrahi standartlarının geliştirilmesine yönelik çok sayıda çalışma yapılmış, enfeksiyonu önlemek amacıyla birçok strateji geliştirilmiştir. ${ }^{[6]}$ Bu konuda daha çok sayıda çalışma yapilmaya devam etmektedir. ${ }^{[3,5,6]} \mathrm{Bu}$ derlemede, PPE'yi önlemede etkisi olan, ameliyathane ortamının standartları, antibiyotik profilaksisi ve kanama kontrolü konuları, literatür bilgileri ışığında irdelenecektir.

- Illetişim adresi: Doç. Dr. İbrahim Azboy, The Rothman Institute at Thomas Jefferson University Department of Orthopaedic Research Sheridan Building, Suite 1000 10th Floor 125 South 9th Street, Philadelphia, PA, USA Tel: +1 267 - 2060918 e-posta: ibrahimazboy@hotmail.com

- Geliștarihi: 1 Mart $2016 \quad$ Kabul tarihi: 1 Mart 2016 


\section{AMELIYATTAN ÖNCE}

\section{Antibiyotik Profilaksisi}

Antibiyotik profilaksisi, PPE gelişmesini önlemede en etkin yöntemdir. ${ }^{[7]}$ Birçok mikroorganizmaya karşı etkili olan ucuz ve biyoyararlılığı iyi olan birinci ve ikinci kuşak sefalosporinler, en etkili antibiyotiklerdir. ${ }^{[7]}$ Metisiline dirençli stafilokok (MRSA) taşıyıcılarında, hastanede yatmakta olan hastalarda ve hastane çalışanlarında, vankomisin veya teikoplanin bir alternatif olarak kullanılabilir. Ayrıca, penisiline alerjisi olan hastalarda vankomisin veya teikoplanin kullanılabilir. Antibiyotik profilaksisine ameliyattan bir saat önce başlanmalı ve antibiyotik dozu hastanın kilosuna göre ayarlanmalıdır. ${ }^{[8]}$ Ameliyat süresinin ilacın bir ya da iki yarı ömründen daha uzun sürmesi, ameliyat sırasında hastaya verilen intravenöz sıvının 2000 ml'den fazla olması veya kanamanın 2000 ml'den fazla olması durumunda, ek antibiyotik dozu uygulanmalıdır. Dirençli bakteri gelişmesini önlemek amacıyla, antibiyotik profilaksisi 24 saatten fazla uygulanmamalıdır. ${ }^{[9]}$

\section{Cilt Hazırlığı}

Ameliyat öncesi en az bir gün öncesinden başlamak üzere, sabun (antimikrobiyal veya antimikrobiyal olmayan) veya bir antiseptikle duş alınması önerilmektedir. [9] Ameliyat öncesi cildin temizlenmesinde kullanılan topikal ajanlar arasında fark olmadığı, ancak alkolün cilt temizleme aşamalarında mutlaka kullanıması gerektiği belirtilmektedir. ${ }^{[10]}$ Birçok randomize kontrollü çalışmada, iyot bazlı ve klorheksidin bazlı solüsyonların etkinlikleri gösterilmiştir. ${ }^{[11]}$ Ameliyat bölgesinin temizlenmesine ek olarak, tüm vücudun ameliyattan bir gün önce klorheksidin glukonat ile temizlenmesinin, MRSA enfeksiyonu ve cerrahi saha enfeksiyonu (CSE) riskini azalttığı gösterilmiştir. ${ }^{[12]}$ Ameliyat bölgesi için, tıraşın gerekli olduğu durumlarda, elektrikli tıraş makinesi ile ameliyattan hemen önce, ancak ameliyat masasının dışında tıraş yapılması gerekmektedir. ${ }^{[13]}$ Stafilokokus aureus taşıyıcılarında CSE gelişme riski fazladır. ${ }^{[14]}$ Taşıyıcıların taranması ve dekolonizayonunun, CSE riskini azalttığı gösterilmiştir. ${ }^{[15]}$ Ancak, hastaların rutin olarak MRSA ve metisiline hassas Stafilokokus aureus (MSSA) taşıyıcılığı açısından taranması konusunda görüş birliği henüz oluşmamıştır. ${ }^{[9]}$

\section{AMELIYAT SIRASINDA}

\section{Ameliyathane Ortamı}

Her ne kadar SCE/PPE'ye neden olan kontaminasyon kaynağının nedeni tam olarak bilinmese de, havadaki partikül sayısının az olmasını teorik alarak destekleyen çok sayıda çalışma bulunmaktadır. ${ }^{[16]}$ Dışarıdan kaynaklanan enfeksiyon riskini azaltmak için birçok strateji mevcuttur. Laminar akım ve tüm vücudu kaplayan uzay giysileri, ortama yayılan partikül sayısını azaltmak için geliştirilmiştir. Ancak, bu iki yöntemin CSE oranlarını azaltmada etkili olup olmadıklarını kesin olarak destekleyen veya reddeden kanıtlar bulunmamaktadır. ${ }^{[17,18]}$ Ameliyat odasında bulunan kişi sayısının çok olması ve kapının sık açılıp kapanması, havanın kontamine olmasına yol açmaktadır. Bu nedenle, ameliyathane odasındaki personel sayısının en az olmasına ve kapının çok gerekli olmadığı sürece açılmamasına özen gösterilmelidir. ${ }^{[19]}$

\section{Yumuşak Doku Hasarının Azaltılması}

Ameliyat sırasında yumuşak doku disseksiyonun titizlikle yapılmasına gereken özen gösterilmelidir. Cildin titiz kapatılmasının, ameliyat sonrası yaranın perfüzyonunu kolaylaştırdığı ve yara drenajı riskini azalttığı, bunun da CSE riskinde azalma ile ilişkili olduğu bulunmuştur. ${ }^{[20,21]}$

\section{Ameliyat Süresi}

Birçok çalışmada, ameliyat süresinin uzaması ile CSE gelişmesi arasında ilişki olduğu gösterilmiştir. ${ }^{[22]} \mathrm{Her}$ ne kadar neden-sonuç ilişkisi net olmasa da, cerrahın tecrübesi, cerrahinin karmaşıklaşması ve ameliyat sırasındaki diğer bazı faktörlerin, ameliyat süresinin uzamasında etkili olduğu söylenebilir. Ameliyatın sonucunu olumsuz yönde etkilemeyecek şekilde, ameliyat süresini kısaltmak için çaba gösterilmelidir.

\section{İrrigasyon Solüsyonları ve Lokal Antibiyotik Kullanımı}

Cerrahi sahadaki patojen sayısını azaltmak için, irrigasyon etkili bir yöntemdir. İrrigasyon solüsyonlarının içeriği, miktarı ve uygulama şekli (yüksek basınç - düşük basınç) net değildir. Yüksek basınçlı yıkama, nekrotik debrisleri etkili bir biçimde uzaklaştırırken, yumuşak dokuya hasar vermesi ve muhtemelen bakterileri daha derinlere doğru itmesi konusunda endişeler bulunmaktadır. Bir çalışmada, ortopedik implant enfeksiyonlarının tedavisinde, yüksek ve düşük basınçlı irrigasyon eşliğinde yapılan debridmanın benzer sonuç sağladığı gösterilmiştir. ${ }^{[23]}$

İrrigasyon solüsyonlarına antibiyotik eklenmesi konusunda farklı görüşler bulunmaktadır. Genel olarak, sinoviyal sıvıda antibiyotik konsantrasyonun düşük olduğu ve aynı zamanda geçici olduğu ve turnike kullanımından da etkilendiği kabul edilmektedir. Whiteside, primer total diz protezi (TDA) $(n=1196)$, primer total kalça protezi (TKA) $(n=631)$, revizyon TPD $(n=285)$ ve revizyon TKP $(n=181)$ uyguladığı toplam 1990 
hastaya (2293 artroplasti vakası), intravenöz sefalosporin profilaksisine ek olarak, ameliyat sırasında vankomisin $1000 \mathrm{mg} / \mathrm{l}$ ve polimiksin 250000 ünite/l içeren solüsyonu ameliyat sırasında lokal olarak kullanmış ve ameliyattan sonra da, ortalama 21 saat süreyle ameliyat sahasına antibiyotikli solüsyonla irrigasyona devem etmiştir. ${ }^{[24]}$ Yazar, morbid obezitesi olan iki hastada cilt altı yağ nekrozu geliştiğini ve sadece bir hastada, dördüncü ayda, derin enfeksiyon geliştiğini bildirmiştir.

Ameliyat sırasında lokal antibiyotik kullanımı ile ilgili, spinal cerrahiden gelen çalışmalar mevcuttur. Strom ve ark., spinal cerrahi ameliyatının sonunda yumuşak dokuya lokal vankomisin tozu uyguladıkları 156 hastada enfeksiyon oranın \%0, vankomisin uygulanmayan 97 hastada ise \%11 olduğunu bildirilmişlerdir. ${ }^{[25]}$ Ancak Tubaki ve ark. ise, spinal cerrahi ameliyatlarında vankomisin tozunun enfeksiyon riskini azaltmada yararı olmadığını belirtmişlerdir.[${ }^{[26]}$ Literatür bilgileri ışığında, rutin olarak irrigasyon solüsyonlarına antibiyotik eklenmesinin veya lokal vankomisin kullanımının dirençli mikroorganizma gelişmesine yol açabileceği göz önünde alınarak, bu iki yöntemin, enfeksiyon nedeniyle revizyon uygulanan vakalar için sınırlı tutulması akılcı olacaktır.

Seyreltilmiş steril betadin solüsyonun kullanılmasının, canlı organizma yükünü azalttığı gösterilmiştir. Brown ve ark., $17,5 \mathrm{ml} \% 10$ betadin içeren $500 \mathrm{ml}$ solüsyon ile $500 \mathrm{ml}$ izotonik solüsyonun birlikte uygulanmasıyla, PPE riskinin anlamlı derecede azaldığını göstermişlerdir. ${ }^{[27]}$ Ancak, betadin solüsyonları, iyot hassasiyeti, yanık, tiroid ve böbrek hastalıkları olan hastalarda kullanılmamalıdır. ${ }^{[28]}$

\section{Kanamayı Azaltma}

Allojenik kan transfüzyonunun bağışıklık sistemi üzerinde değiştirici etkisi olduğu ve PPE riskinde artış ile ilişkili olduğu gösterilmiştir. ${ }^{[29]}$ Bu risk, ayrıca, transfüzyon sayısı ile de ilişkilidir. Mümkün olduğunca allojenik kan transfüzyonundan kaçınılmalı, kan transfüzyonu kararı, hemoglobin seviyesinden daha çok, klinik belirtilere göre verilmelidir. Kan transfüzyon oranını azaltmak için, mevcut olan aneminin düzeltilmesi ve genel anestezi yerine hipotansif spinal veya epidural anestezi yöntemleri tercih edilmelidir. Son zamanlarda yaygınlık kazanan lokal veya iv traneksamik asit uygulamasının, diz ve kalça artroplastisi ameliyatlarında kan kaybını ve böylece kan transfüzyon ihtiyacını azalttığı, buna rağmen venöz tromboembolik olaylarda artışa neden olmadığı bildirilmiştir. ${ }^{[30]}$ Kanama kontrolünde kullanılan yeni yöntemlerin ve hematom oluşumuna daha az neden olan tromboprofilaksi seçeneklerinin giderek daha fazla tercih edilmesine paralel olarak, dren kullanımı daha az tercih edilmeye başlanmıştır.
Nitekim, dren kullanılmayan olgularda, dren kullanılan olgulara göre kan transfüzyonu ihtiyacının azaldığı gösterilmiştir. ${ }^{[31]}$

\section{Diğer Önlemler}

Cerrah, ameliyattan önce mekanik temizlikle birlikte, bir antiseptik solüsyonla ellerini en az iki dakika süreyle yıkamalıdır. Çift eldiven kullanılmalı ve her 90 dakikada bir değiştirilmelidir. Cildi örtmek için drep kullanılmadır. Setler, kontaminasyonu azaltmak amacıyla ameliyattan hemen önce açılmalıdır. Ayrıca, uzun süre kullanılmayacak olan setler, masadan aşağıya sarkmayan bir steril örtü ile kapatılmalıdır. Cilt kesisinden sonra bistüri değiştirilmelidir. ${ }^{[9]}$ Kontaminasyonu azaltmak amacıyla, aspiratör uçları her 60 dakikada bir değiştirilmelidir. Benzer şekilde, kontaminasyonu önlemek için sıvılar, üstü açık geniş kaplarda bekletilmemelidir. Hasta, ameliyat sırasında normotermik tutulmaya çalışılmalıdır. Revizyon olgularında ve enfeksiyon riski yüksek olan olgularda, çimentoya antibiyotik eklenmesi önerilmektedir. ${ }^{[9]}$

\section{AMELIYAT SONRASI DÖNEM}

\section{Yara Bakımı}

Yara ile ilişkili sorunlarla PPE arasında kuvvetli bir ilişki bulunmaktadır. Yara bakımında ana amaç, yara iyileşmesini hızlandırmak ve yaranın dış kaynaklı kontaminasyonunu önlemektir. Yeterli kanıtlar olmadığından dolayı, elektif artroplasti ameliyatlarında en iyi cilt kapama yöntemi konusunda kesin bir görüş birliği bulunmamaktadır. Bununla birlikte, Uluslararası Ortak Görüş Toplantısı'nda, akut yara sorunları için yeniden ameliyat edilen hastalarda, non-filaman ve emilemeyen dikiş materyallerin tercih edilmesi önerilmiştir. ${ }^{[32]}$

En uygun yara örtüsünün ne olduğu konusu netlik kazanmamıştır. ${ }^{[9]}$ Son zamanlarda yapılan iki randomize kontrollü çalışmada, oklüsif antimikrobiyal yara örtülerinin, standart yara örtülerine göre, yara komplikasyonlarında ve pansuman değişimi sayılarında anlamlı azalma sağladığı gösterilmiştir. ${ }^{[33]}$

\section{Yara Drenajının Yönetimi}

Yara drenajının uzun sürmesi ile CSE riski gelişimi arasında ilişki vardır. Bu nedenle, yara enerjik bir şekilde tedavi edilmelidir. Ameliyattan sonra drenajın üç günden daha fazla devam ettiği durumlarda, başlangıçta baskılı pansuman veya negatif basınçlı yara tedavisi uygulanabilir. Nitekim, bu yöntemlerin seroma oluşumunu ve yara drenajını azalttığı gösterilmiştir. ${ }^{[34]}$ $\mathrm{Bu}$ yöntemler erken uygulandığı takdirde, birçok hastada ek cerrahi girişimlere gereksinim kalmayacaktır. 
Yara drenajının 5-7 günden daha fazla sürdüğü durumlarda, geç PPE riskini azaltmak için, yaranın erken irrigasyon ve debridmanı uygulanmalıdır. ${ }^{[9]}$

\section{Hematomun Önlenmesi}

Elektif artroplastiden sonra hematom oluşumu, PPE riskini arttıran ciddi bir komplikasyondur. Bu nedenle, hematom oluşumu en aza indirmek için her türlü çaba gösterilmelidir. Bunların başında, ameliyat sırasında titiz hemostaz yapılması ve eğer mümkünse yüksek etkinlik gösteren antikoagülanların kullanılmaması gelmektedir. ${ }^{[5]}$ Aspirinin, venöz tromboembolizm riskinin standart olduğu hastalarda, diz ve kalça artroplastisi sonrasında tromboprofilakside güvenli ve etkin olduğu gösterilmiştir. ${ }^{[35]}$ Aspirinin diz ve kalça artroplastisinden sonra VTE profilaksisi için kullanımı, Amerikan Ortopedik Cerrahlar Akademisi tarafından da desteklenmektedir. ${ }^{[36]}$

Total eklem artroplastisi sonrasında gelişen PPE, morbidite ve mortaliteye yol açan ciddi bir komplikasyondur. Illk adım, periprostetik enfeksiyon gelişimini önlemek olmalıdır. Bu amaçla, hasta ameliyattan önce ideal hale getirilmeli ve antibiyotik profilaksisine cilt kesisinden bir saat önce başlanmalıdır. İnokule olan patojenlerin sayısını azaltmak için, hastanın cildi hazırlanmalı, ayrıca ameliyathane odasının havasının temizliği sağlanmalıdır. Cerrahi, yumuşak dokuya en az hasarla uygulanmalı, kanama en aza indirilmeli ve hematom oluşumu önlenmelidir. Ameliyat sonrasında yara iyileşmesinde karşılaşılan sorunlar erken ve ciddi bir şekilde tedavi edilmeli ve yüksek etkinlikli antikoagülanlar, sadece gerekli olan durumlarda tercih edilmelidir. Sözü edilen önlemlerin, bir kontrol listesi haline getirilerek, ameliyata başlamadan önce, ameliyat sırasında ve ameliyattan sonra bir ekip tarafindan denetlenmesi yararlı olacaktır. Tüm önlemler alındığında, PPE riskini minimum tutmak mümkün olabilir.

\section{KAYNAKLAR}

1. Azboy I, Demirtaş $A$, Bulut $M$, Oztürkmen $Y$, Sükür $E$, Caniklioğlu M. Long-term results of porous-coated cementless total knee arthroplasty with screw fixation. Acta Orthop Traumatol Turc 2013;47:347-53.

2. O'Toole P, Maltenfort MG, Chen AF, Parvizi J. Projected Increase in Periprosthetic Joint Infections Secondary to Rise in Diabetes and Obesity. J Arthroplasty 2016;31(1):7-10. Crossref

3. Gehrke $T$, Alijanipour $P$, Parvizi J. The management of an infected total knee arthroplasty. Bone Joint J 2015;97-B(10 Suppl A):20-9. Crossref

4. Hackett DJ, Rothenberg AC, Chen AF, Gutowski C, Jaekel D, Tomek IM, Parsley BS, Ducheyne P, Manner PA. The economic significance of orthopaedic infections. J Am Acad Orthop Surg 2015;23;Suppl:S1-7. Crossref
5. Heller S, Rezapoor M, Parvizi J. Minimising the risk of infection: a peri-operative checklist. Bone Joint J 2016;98-B(1 Suppl A):18-22. Crossref

6. Rezapoor M, Parvizi J. Prevention of Periprosthetic Joint Infection. J Arthroplasty 2015;30(6):902-7. Crossref

7. Voigt J, Mosier M, Darouiche R. Systematic review and meta-analysis of randomized controlled trials of antibiotics and antiseptics for preventing infection in people receiving primary total hip and knee prostheses. Antimicrob Agents Chemother 2015;59(11):6696-707. Crossref

8. van Kasteren ME, Manniën J, Ott A, Kullberg BJ, de Boer AS, Gyssens IC. Antibiotic prophylaxis and the risk of surgical site infections following total hip arthroplasty: timely administration is the most important factor. Clin Infect Dis 2007;44(7):921-7.

9. Parvizi J, Gehrke T, Chen AF. Proceedings of the International Consensus on Periprosthetic Joint Infection. Bone Joint J 2013;95-B(11):1450-2. Crossref

10. Tokarski AT, Blaha D, Mont MA, Sancheti P, Cardona L, Cotacio GL, Froimson M, Kapadia B, Kuderna J, López JC, Matar WY, McCarthy J, Morgan-Jones R, Patzakis M, Schwarzkopf R, Shahcheraghi GH, Shang X, Virolainen $\mathrm{P}$, Wongworawat MD, Yates A Jr. Perioperative skin preparation. J Orthop Res 2014;32;Suppl 1:S26-30. Crossref

11. Hakkarainen TW, Dellinger EP, Evans HL, Farjah F, Farrokhi E, Steele SR, Thirlby R, Flum DR; Surgical Care and Outcomes Assessment Program Collaborative. Comparative effectiveness of skin antiseptic agents in reducing surgical site infections: a report from the Washington State Surgical Care and Outcomes Assessment Program. J Am Coll Surg 2014;218(3):336-44. Crossref

12. Climo MW, Yokoe DS, Warren DK, Perl TM, Bolon M, Herwaldt LA, Weinstein RA, Sepkowitz KA, Jernigan JA, Sanogo K, Wong ES. Effect of daily chlorhexidine bathing on hospital-acquired infection. N Engl J Med 2013;368(6):53342. Crossref

13. Tanner J, Norrie P, Melen K. Preoperative hair removal to reduce surgical site infection. Cochrane Database Syst Rev 2011;(11):CD004122. Crossref

14. Wertheim HF, Melles DC, Vos MC, van Leeuwen W, van Belkum A, Verbrugh HA, Nouwen JL. The role of nasal carriage in Staphylococcus aureus infections. Lancet Infect Dis 2005;5(12):751-62.

15. Weiser MC, Moucha CS. The Current State of Screening and Decolonization for the Prevention of Staphylococcus Aureus Surgical Site Infection After Total Hip and Knee Arthroplasty. J Bone Joint Surg Am 2015;97(17):1449-58. Crossref

16. Evans RP. Current concepts for clean air and total joint arthroplasty: laminar airflow and ultraviolet radiation: a systematic review. Clin Orthop Relat Res 2011;469(4):94553. Crossref

17. Gastmeier P, Breier AC, Brandt C. Influence of laminar airflow on prosthetic joint infections: a systematic review. J Hosp Infect 2012;81(2):73-8. Crossref

18. Hooper GJ, Rothwell AG, Frampton C, Wyatt MC. Does the use of laminar flow and space suits reduce early deep infection after total hip and knee replacement?: the ten-year results of the New Zealand Joint Registry. J Bone Joint Surg Br 2011;93(1):85-90. Crossref

19. Mears SC, Blanding R, Belkoff SM. Door Opening Affects Operating Room Pressure During Joint Arthroplasty. Orthopedics 2015;38(11):e991-4. Crossref 
20. Wyles CC, Jacobson SR, Houdek MT, Larson DR, Taunton MJ3, Sim FH, Sierra RJ, Trousdale RT. The Chitranjan Ranawat Award: Running Subcuticular Closure Enables the Most Robust Perfusion After TKA. A Randomized Clinical Trial. Clin Orthop Relat Res 2016;474(1):47-56. Crossref

21. Patel RM, Cayo M, Patel A, Albarillo M, Puri L. Wound complications in joint arthroplasty: comparing traditional and modern methods of skin closure. Orthopedics 2012;35(5):e641-6. Crossref

22. Namba RS, Inacio MC, Paxton EW. Risk factors associated with deep surgical site infections after primary total knee arthroplasty: an analysis of 56,216 knees. J Bone Joint Surg Am 2013;95(9):775-82. Crossref

23. Muñoz-Mahamud E, García S, Bori G, Martínez-Pastor JC, Zumbado JA, Riba J, Mensa J, Soriano A. Comparison of a low-pressure and a high-pressure pulsatile lavage during débridement for orthopaedic implant infection. Arch Orthop Trauma Surg 2011;131(9):1233-8. Crossref

24. Whiteside LA. Prophylactic peri-operative local antibiotic irrigation. Bone Joint J 2016;98-B(1 Suppl A):23-6. Crossref

25. Strom RG, Pacione D, Kalhorn SP, Frempong-Boadu AK. Lumbar laminectomy and fusion with routine local application of vancomycin powder: decreased infection rate in instrumented and non-instrumented cases. Clin Neurol Neurosurg 2013;115(9):1766-9. Crossref

26. Tubaki VR, Rajasekaran S, Shetty AP. Effects of using intravenous antibiotic only versus local intrawound vancomycin antibiotic powder application in addition to intravenous antibiotics on postoperative infection in spine surgery in 907 patients. Spine (Phila Pa 1976) 2013;38(25):2149-55. Crossref

27. Brown NM, Cipriano CA, Moric M, Sporer SM, Della Valle CJ. Dilute betadine lavage before closure for the prevention of acute postoperative deep periprosthetic joint infection. J Arthroplasty 2012;27(1):27-30. Crossref

28. Chundamala J, Wright JG, The efficacy and risks of using povidone-iodine irrigation to prevent surgical site infection: an evidence-based review. Can J Surg 2007;50(6):473-81.
29. Innerhofer P, Klingler A, Klimmer C, Fries D, Nussbaumer W. Risk for postoperative infection after transfusion of white blood cell-filtered allogeneic or autologous blood components in orthopedic patients undergoing primary arthroplasty. Transfusion 2005;45(1):103-10.

30. Melvin JS, Stryker LS, Sierra RJ. Tranexamic Acid in Hip and Knee Arthroplasty. J Am Acad Orthop Surg 2015;23(12):73240. Crossref

31. Parker MJ, Livingstone V, Clifton R, McKee A. Closed suction surgical wound drainage after orthopaedic surgery. Cochrane Database Syst Rev 2007;(3):CD001825.

32. Ghanem E, Heppert V, Spangehl M, Abraham J, Azzam K, Barnes L, Burgo FJ, Ebeid W, Goyal N, Guerra E, Hitt K, Kallel S, Klein G, Kosashvili Y, Levine B, Matsen L, Morris MJ, Purtill JJ, Ranawat C, Sharkey PF, Sierra R, Stefansdottir A. Wound management. J Arthroplasty 2014;29(2 Suppl):84-92. Crossref

33. Springer BD, Beaver WB, Griffin WL, Mason JB, Odum SM. Role of Surgical Dressings in Total Joint Arthroplasty: A Randomized Controlled Trial. Am J Orthop (Belle Mead NJ) 2015;44(9):415-20.

34. Pachowsky M, Gusinde J, Klein A, Lehrl S, Schulz-Drost S, Schlechtweg P, Pauser J, Gelse K, Brem MH. Negative pressure wound therapy to prevent seromas and treat surgical incisions after total hip arthroplasty. Int Orthop 2012;36(4):719-22. Crossref

35. Huang R, Buckley PS, Scott B, Parvizi J, Purtill JJ. Administration of Aspirin as a Prophylaxis Agent Against Venous Thromboembolism Results in Lower Incidence of Periprosthetic Joint Infection. J Arthroplasty 2015;30(9 Suppl):39-41. Crossref

36. Jacobs JJ, Mont MA, Bozic KJ, Della Valle CJ, Goodman SB, Lewis CG, Yates AC Jr, Boggio LN, Watters WC 3rd, Turkelson CM, Wies JL, Sluka P, Hitchcock K. American Academy of Orthopaedic Surgeons clinical practice guideline on: preventing venous thromboembolic disease in patients undergoing elective hip and knee arthroplasty. J Bone Joint Surg Am 2012;94(8):746-7. Crossref 